\title{
Detection and preliminary characterization of two enzymes involved in biosynthesis of platelet-activating factor in mouse oocytes, zygotes and preimplantation embryos: dithiothreitol-insensitive cytidinediphosphocholine: 1-O-alkyl-2-acetyl-sn-glycerol cholinephosphotransferase and acetyl-coenzyme A:1-O-alkyl-2-lyso-sn-glycero-3-phosphocholine acetyltransferase
}

\author{
X. E. Wells and C. O'Neill* \\ Human Reproduction Unit, Royal North Shore Hospital of Sydney, St Leonards, NSW 2065, \\ Australia
}

\begin{abstract}
The aim of this study was to determine whether the final enzymes in the two biosynthetic pathways for platelet-activating factor (PAF) (the 'de novo' and the 'membrane remodelling' pathways) are present in mouse embryos, zygotes and oocytes. The enzymes are dithiothreitol-insensitive cytidinediphosphocholine: 1-O-alkyl-2-acetylsn-glycerol cholinephosphotransferase (cholinephosphotransferase) in the de novo pathway and acetyl-coenzyme A:1-O-alkyl-2-lyso-sn-glycero-3-phosphocholine acetyltransferase (acetyltransferase) in the membrane remodelling pathway. Activity of both enzymes was detected in the unfertilized oocyte, the zygote and also in the preimplantation embryo (48, 72 and $96 \mathrm{~h}$ after the ovulatory injection of hCG). In both cases the activity was destroyed by boiling and increased linearly with incubation time and the concentration of embryo homogenate present, indicating that the reactions were catalysed by enzymes. The product of the reactions was confirmed as PAF using HPLC and structural analyses by enzymatic digestion. Cholinephosphotransferase required $\mathrm{Mg}^{2+}$ and was inhibited by $\mathrm{Ca}^{2+}$, while acetyltransferase required the presence of $\mathrm{NaF}$ (a phosphatase inhibitor). The activity of cholinephosphotransferase was similar in unfertilized oocytes and zygotes, and did not change significantly with advancing developmental stage in preimplantation embryos. Acetyltransferase had a significantly lower specific activity $(0.078 \pm 0.044 \mathrm{fmol}$ PAF per oocyte per min, mean \pm SEM) in unfertilized oocytes than in zygotes of corresponding age $(0.358 \pm 0.097 \mathrm{fmol}$ PAF per zygote per min) $(P<0.03)$. During the preimplantation period, acetyltransferase activity was higher at the two-cell stage $(0.578 \pm 0.245 \mathrm{fmol}$ PAF per embryo per min) than for compacted embryos $(0.097 \pm 0.056)$, while blastocysts displayed an intermediate activity $(0.201 \pm 0.002)$. For both enzymes, activity was variable at all developmental stages studied. The results indicate that the enzymes that catalyse the final step in both biosynthetic pathways are present within the oocyte and early embryo, while the activation of acetyltransferase following fertilization indicates that this enzyme may be of regulatory significance in the initiation of biosynthesis of PAF by zygotes.
\end{abstract}

\section{Introduction}

Platelet-activating factor (PAF; 1-O-alkyl-2-acetyl-sn-glycero-3phosphocholine) is released by the preimplantation embryos of a number of species (mice: O'Neill, 1985a; humans: Collier et al., 1988; sheep: Battye et al., 1991). It has been detected using several different methods including a whole-animal

*Correspondence.

Received 9 November 1993. bioassay (O'Neill et al., 1987), in vitro bioassays (Collier et al., 1988), radioimmunoassays (Ammit and O'Neill, 1991) and mass spectroscopy (Kodama et al., 1989), and has been independently confirmed for the mouse (Adamson et al., 1991) and human (Punjabi et al., 1990) embryo. However, some workers (Amiel et al., 1989; Smal et al., 1990) have failed to demonstrate the release of PAF by embryos. This conflict and a consideration of its possible causes have been considered in detail in a recent review by O'Neill (1993). 


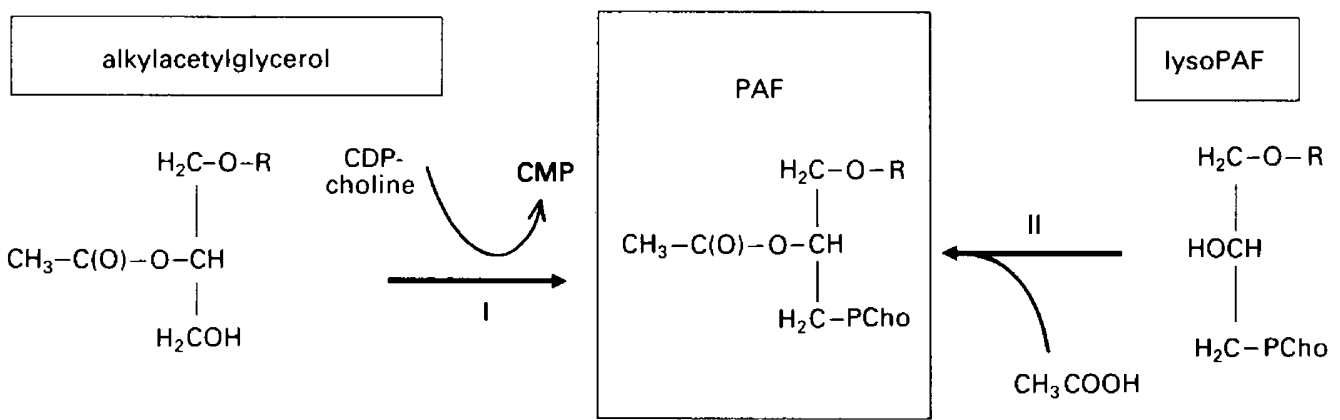

Fig. 1. The reactions catalysed by cholinephosphotransferase (I) and acetyltransferase (II) involved in biosynthesis of platelet-activating factor (PAF) in mouse embryos: CDP: cytidine diphosphate; CMP: cytidine monophosphate; PCho: phosphocholine; R: C16-C18.

Two-cell mouse embryos cultured in vitro were shown to convert radiolabelled precursors into radiolabelled embryoderived PAF (Wells and O'Neill, 1992). The precursors included intermediates of known PAF biosynthetic pathways (long-chain alcohols, lysoPAF, hexadecylacetylglycerol). Studies in various cell types indicate that PAF synthesis may occur via one of two biosynthetic pathways: the 'de novo' and 'membrane remodelling' pathways (for review see Snyder, 1990). The immediate precursors of PAF in the de novo pathway are 1-O-alkyl-2-acetyl-sn-glycerol (alkylacetylglycerol) and cytidinediphosphocholine. In the membrane remodelling pathway, the substrates are 1-O-alkyl-2-lyso-sn-glycero-3phosphocholine (lysoPAF) and acetyl-coenzyme A (acetyl$\mathrm{CoA}$ ). These reactions are shown in Fig. 1 and are catalysed by dithiothreitol-insensitive cytidinediphosphocholine: $1-O$-alkyl2-acetyl-sn-glycerol cholinephosphotransferase (EC 2.7.8.16, cholinephosphotransferase), and by acetyl-coenzyme $\mathrm{A}$ : 1-O-alkyl-2-lyso-sn-glycero-3-phosphocholine acetyltransferase (EC 2.3.1.67, acetyltransferase), respectively (Snyder, 1990).

This paper reports the modification of assays for cholinephosphotransferase and acetyltransferase to allow detection of their activity in mouse embryo extracts. Preliminary characterization of the activity of the enzyme is performed and their activity in unfertilized oocytes, zygotes and preimplantation embryos is examined.

\section{Materials and Methods}

\section{Materials}

1-O-[Hexadecyl-1' $\left.2{ }^{\prime}-{ }^{3} \mathrm{H}(\mathrm{N})\right]$-2-acetyl-sn-glycero-3-phosphocholine $\left({ }^{3} \mathrm{H}\right] \mathrm{PAF}$; specific activity, $\left.2220.0 \mathrm{GBq} \mathrm{mmol}^{-1}\right)$, 1-O-[alkyl-1'2 $\left.{ }^{\prime}{ }^{3} \mathrm{H}\right]$-sn-glyceryl-3-phosphocholine $\left({ }^{3} \mathrm{H}\right] \mathrm{lyso} \mathrm{PAF}$; specific activity, $1924.0 \mathrm{GBq} \mathrm{mmol}^{-1}$ ), [acetyl $\left.{ }^{3} \mathrm{H}\right] \mathrm{CoA}$ (specific activity, $173.9 \mathrm{GBq} \mathrm{mmol}^{-1}$ ) and $\left[\right.$ methyl $-{ }^{14} \mathrm{C}$ ] cytidinediphosphocholine (specific activity, $2.1 \mathrm{GBq} \mathrm{mmol}{ }^{-1}$ ) were supplied by NEN (Wilmington, DE). Sigma Chemical Co (St Louis, MO) supplied L- $\alpha$-lysophosphatidylcholine, 1-Oalkyl (lysoPAF) and acetyl-CoA, Na salt. BSA was supplied by Pentex, Miles Inc (Kankakee, IL) and 1-O-hexadecyl-2acetyl-sn-glycerol was purchased from Nova Biochem AG (Laufelfingen). All organic solvents were HPLC grade (BDH, Poole). All other chemicals used were the best grade for the purpose.

\section{Embryo collection}

Random-bred Swiss albino mice of the Quackenbush strain (Gore Hill Research Laboratories, NSW), 6-8 weeks old, were superovulated i.p. with 10 iu pregnant mares' serum gonadotrophin (Folligon, Intervet International, Boxmeer) followed $48 \mathrm{~h}$ later by an i.p. injection of $10 \mathrm{iu}$ hCG (Chorulon, Intervet). They were either left unmated or paired with males of proven fertility overnight; the presence of a copulation plug indicated day $I$ of pregnancy.

Unfertilized oocytes and zygotes were collected $24 \mathrm{~h}$ after hCG administration. The cumulus masses were released from the oviduct into Hepes-buffered human tubal fluid medium (Quinn et al., 1985) supplemented with $3 \mathrm{mg} \mathrm{BSA} \mathrm{ml} \mathrm{m}^{-1}$ (Hepes-HTF/BSA). Oocytes or zygotes were freed from their cumulus masses by brief exposure to 300 iu hyaluronidase (Sigma Chemical Co) in Hepes-HTFM/BSA. They were then thoroughly washed in five changes of Hepes-HTFM/BSA. Embryos at the two-cell stage were recovered by flushing the oviducts of mated animals $48 \mathrm{~h}$ after hCG injection (day 2). Compacted embryos were collected $72 \mathrm{~h}$ after hCG administration and blastocysts were collected from the uterus approximately $96 \mathrm{~h}$ after hCG administration. In every case embryos were collected in Hepes-HTF/BSA. Embryos were washed twice in bicarbonate-buffered human tubal fluid medium (Quinn

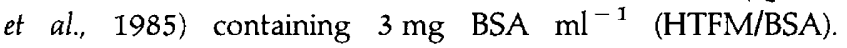
Embryos were transferred to the appropriate buffer on ice and then prepared for assay.

\section{Preparation of embryo extracts}

All operations were performed at $4^{\circ} \mathrm{C}$ and all buffers contained $3 \mathrm{mg} \mathrm{BSA} \mathrm{ml}^{-1}$. When performing dithiothreitolinsensitive cholinephosphotransferase assays, embryo extracts were prepared in $0.1 \mathrm{~mol}$ Tris $\mathrm{l}^{-1}$ containing $0.5 \mathrm{mmol}$ EGTA $\mathrm{I}^{-1}, 10 \mathrm{mmol} \mathrm{MgCl}_{2} \mathrm{l}^{-1}$ and $5 \mathrm{mmol}$ dithiothreitol (DTT) $\mathrm{l}^{-1}$ (all from Sigma Chemical Co), pH 8.0 (Alonso et al., 1982). Embryo extracts in which acetyltransferase activity was measured were prepared in $20 \mathrm{mmol}$ Tris $\mathrm{I}^{-1}$ containing $50 \mathrm{mmol}$ $\mathrm{NaF}^{-1}$ (Sigma Chemical Co) and $5 \mathrm{mmol}$ DTT ${ }^{-1}$, pH 7.4 (Lenihan and Lee, 1984; Lee, 1985).

Embryos were transferred in a minimal volume using a drawn Pasteur pipette to the appropriate buffer in a microcentrifuge tube. Generally, embryos were added at the rates of 2 embryos $\mu \mathrm{l}^{-1}$ (acetyltransferase assay) and 1 embryo $\mu l^{-1}$ 
(cholinephosphotransferase). The mixture was immediately sonicated on ice with a microtip probe of a Heat Systems UItrasonics W-385 sonicator (New York) on setting 1 for $10 \mathrm{~s}$. Aliquots of the mixture were used immediately in the appropriate enzyme assay.

\section{Enzyme assays}

All assays were performed in microcentrifuge tubes and incubated at $37^{\circ} \mathrm{C}$. The assays were initiated by the addition of embryo homogenate and stopped by freezing. Assays were generally performed at least in duplicate. Blank reactions contained aliquots of the preparation buffer without embryos. All assay buffers contained $3 \mathrm{mg} \mathrm{BSA} \mathrm{ml}^{-1}$.

Cholinephosphotransferase. This assay is based on the method described by Alonso et al. (1982) with modifications. In the standard assay, $20 \mu \mathrm{l}$ of embryo extract was brought to a final volume of $27 \mu \mathrm{l}$ while being supplemented with hexadecylacetylglycerol (added in $\mathrm{I} \mu \mathrm{l}$ ethanol) and [methyl${ }^{14} \mathrm{Clcytidinediphosphocholine}(3.7 \mathrm{kBq})$ to give final concentrations of $52 \mu \mathrm{mol}{ }^{-1}$ and $66 \mu \mathrm{mol} \mathrm{l}{ }^{-1}$, respectively.

Acetyltransferase. This assay is based on procedures described by Lenihan and Lee (1984) and Lee (1985) with modifications. A $15 \mu \mathrm{l}$ aliquot of embryo extract was brought to a final volume of $28 \mu \mathrm{l}$ with $0.1 \mathrm{~mol}$ Tris $\mathrm{l}^{-1}, \mathrm{pH} 6.9$, containing lysoPAF (added in $1 \mu \mathrm{l}$ ethanol) and [acetyl- ${ }^{3} \mathrm{H}$ ] CoA $(3.7 \mathrm{kBq})$, to give final concentrations of $24 \mu \mathrm{mol} \mathrm{l} \mathrm{l}^{-1}$ and $215 \mathrm{~mol} \mathrm{l}^{-1}$, respectively.

\section{Extraction and HPLC of radiolabelled PAF from assay mixtures}

Each assay sample was thawed by the addition of $0.43 \mathrm{ml}$ $0.1 \mathrm{~mol}$ Tris $1^{-1}, \mathrm{pH} 7.4$, containing $3 \mathrm{mg} \mathrm{BSA} \mathrm{ml}{ }^{-1}$ and allowed to stand at room temperature for approximately $10 \mathrm{~min}$. The samples were then mixed and $0.4 \mathrm{ml}$ was extracted as described by Wells and O'Neill (1992) by a modified Bligh-Dyer technique (Bligh and Dyer, 1959).

The resultant lipid extracts were resuspended in $120 \mu \mathrm{l}$ methanol and chromatographed on a Partisil strong cation exchange HPLC column, $10 \mu \mathrm{m}, 250 \mathrm{~mm} \times 4.6 \mathrm{~mm}$ (Whatman, Clifton, NJ). Phospholipids were eluted isocratically with a mobile phase of acetonitrile:methanol:water (300:150:35 v:v:v) at a flow of $1.5 \mathrm{ml} \mathrm{min}{ }^{-1}$ (Wells and O'Neill, 1992). Eluant was collected (1.5 ml fractions) and the amount of radioactivity in each fraction was determined by liquid scintillation counting. For each sample, the distribution of radiolabel throughout the elution profile was compared with the known distribution of $\left[{ }^{3} \mathrm{H}\right] \mathrm{PAF}$. PAF production was identified as the amount of radioactivity eluted in the same region as $\left[{ }^{3} \mathrm{H}\right] \mathrm{PAF}$ after subtraction of the blank. The elution profiles of other phospholipids (phosphatidylcholine, phosphatidylethanolamine, lysophosphatidylcholine, sphingomyelin and $\left[{ }^{3} \mathrm{H}\right] \mathrm{l}$ ysoPAF) were also examined to ensure that they did not co-migrate with PAF, as has been described by Wells and O'Neill (1992). These phospholipids plus $\left[{ }^{3} \mathrm{H}\right] \mathrm{PAF}$ were routinely chromatographed before and after a series of unknown samples to determine the retention time of PAF. Unlabelled and labelled standards were detected by UV absorbance at $203 \mathrm{~nm}$ and liquid scintillation counting, respectively. $\left[{ }^{3} \mathrm{H}\right] \mathrm{PAF}$ could not be used as an internal standard; the efficiency of the extraction and HPLC were therefore monitored by routinely incubating trace amounts of $\left[{ }^{3} \mathrm{H}\right] \mathrm{PAF}$ (approximately 1500 d.p.m. in $1 \mu$ l ethanol) in the appropriate buffer and processing in parallel. Aliquots of these $\left[{ }^{3} \mathrm{H}\right] \mathrm{PAF}-$ containing samples were taken before extraction, at various stages of the procedure, and the amount of radioactivity present was determined. The percentage recovery of $\left[{ }^{3} \mathrm{H}\right] \mathrm{PAF}$ was used to correct for the loss of activity during extraction and chromatography. The mean ( \pm SEM) recovery of a $\left[{ }^{3} \mathrm{H}\right] \mathrm{PAF}$ tracer from assay mixtures was $58.6 \%( \pm 2.2 \%)$ after extraction and HPLC. This value is similar to the percentage recovery of $\left[{ }^{3} \mathrm{H}\right] \mathrm{PAF}$ tracer from HTFM/BSA previously reported (Wells and O'Neill, 1992).

\section{Identification of radiolabelled PAF}

The ${ }^{14} \mathrm{C}$-labelled product resulting from the phosphocholinetransferase reaction was subject to enzymatic hydrolysis by phospholipase $A_{2}$ (bee venom; EC 3.1.1.4., Sigma Chemical Co), as described by Wykle et al. (1988). If the substrate had been incorporated into PAF, the product of phospholipase $A_{2}$ digestion would be $\left[{ }^{14} \mathrm{CllysoPAF}\right.$. After hydrolysis, reextraction and chromatography on the HPLC system described above was performed. The distribution of label in the elution profile was determined by liquid scintillation counting and compared with that of authentic lysoPAF.

Hydrolysis by phospholipase C (Bacillus cerus, EC. 3.1.4.3., grade I, Boehringer Mannheim, Castle Hill, NSW) of the radiolabelled product of the acetyltransferase reaction was performed as previously described (Wells and O'Neill, 1992). Zones of the TLC plates were scraped and radioactivity was eluted with hexane:diethylether $(\mathrm{I}: \mathrm{I}, \mathrm{v}: \mathrm{V})$. The distribution of the label was compared with that of $\left[{ }^{3} \mathrm{H}\right]$ alkylacetylglycerol.

For both treatments, controls containing the appropriate labelled product but no phospholipase $\mathrm{A}_{2}$ or phospholipase $\mathrm{C}$ were set up and incubated to ensure that no non-enzymatic hydrolysis occurred.

\section{Statistical analyses}

Data were tested for homogeneity by the Shapiro-Wilk test. The effect of changes to incubation conditions on enzyme activity was assessed where necessary by $t$ tests between the treatment and its respective control value. The results are presented as percentage relative changes in activity. For the direct comparison of activity in oocytes and zygotes $24 \mathrm{~h}$ after hCG administration, $t$ tests were also performed. The activity at different development stages was assessed by analysis of variance and, where applicable, multiple comparisons of means were made by the least significant difference test. All analyses were performed using the SPIDA statistics package, Statistical Computing Laboratory Pty Ltd, Eastwood, NSW.

\section{Results}

Two-cell mouse embryos ( $48 \mathrm{~h}$ after hCG administration) were used for the development of enzyme assays and preliminary 


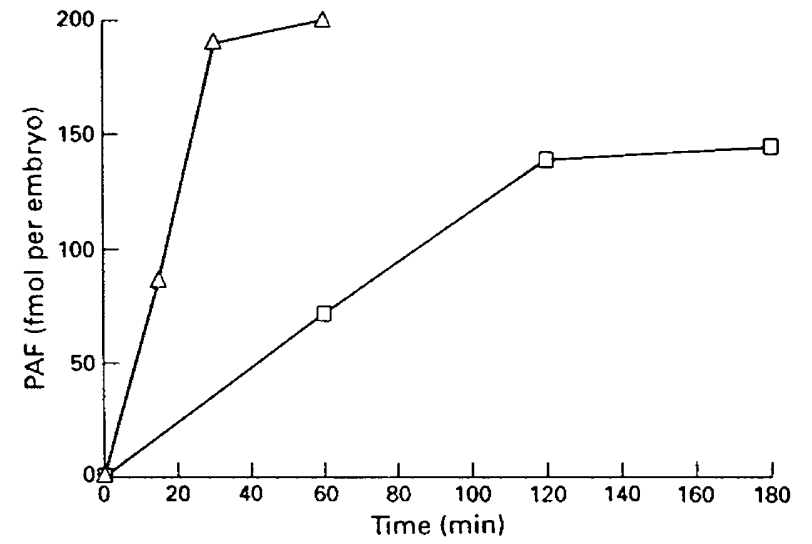

Fig. 2. The influence of incubation time (at $37^{\circ} \mathrm{C}$ ) on the activity of $(\square)$ acetyltransferase and $(\Delta)$ cholinephosphotransferase in mouse embryos. Cholinephosphotransferase assays were incubated for a maximum of $60 \mathrm{~min}$ and acetyltransferase assays for up to $180 \mathrm{~min}$. Each point represents the mean of two experiments, with each experiment performed in duplicate. PAF: platelet-activating factor.

characterization of activity. Enzyme activity was detected by conversion of substrate into radiolabelled PAF as detected by HPLC. The results are expressed as the fmol of $\left[{ }^{3} \mathrm{H}\right] \mathrm{PAF}$ or $\left[{ }^{14} \mathrm{C} P \mathrm{PAF}\right.$ produced in the acetyltransferase or cholinephosphotransferase assays, respectively.

In preliminary experiments it was found that when embryos were prepared in buffer without exogenous BSA, a significant proportion of the incorporated label co-migrated with lysoPAF. Furthermore, the embryo extracts could convert approximately $15 \%$ of exogenous $\left[{ }^{3} \mathrm{H}\right] \mathrm{PAF}$ into lysoPAF, suggesting the presence of an acetylhydrolase activity. Addition of $3 \mathrm{mg}$ BSA ml ${ }^{-1}$ to the reaction mixture consistently caused the complete inhibition of this hydrolysis. Thus, in all experiments reported here, exogenous BSA was present in enzyme extracts to allow total enzyme activity to be assessed.

The cholinephosphotransferase activity that produced PAF from hexadecylacetylglycerol and $\left[{ }^{14} \mathrm{C}\right]$ cytidinediphosphocholine increased with incubation time, reaching an apparent maximum by $30 \mathrm{~min}$ (Fig. 2), and with the concentration of embryo homogenate present (Fig. 3). Its activity was destroyed by boiling and required the presence of exogenous alkylacetylglycerol (Table 1). It was not affected $(P>0.05)$ by the absence of either EGTA or DTT from the buffers (Table 1). However, the absence of $\mathrm{Mg}^{2+}$ significantly reduced activity $(P<0.01)$ while the presence of $100 \mu \mathrm{mol} \mathrm{Ca}{ }^{2+} 1^{-1}$ in the absence of EGTA also significantly reduced $(P<0.01)$ activity to $6 \%$ of control activity (Table 1 ). Standard conditions for assessing the specific activity of cholinephosphotransferase were defined as the activity in the extracts of 20 embryos or oocytes after incubation for $30 \mathrm{~min}$ in the reaction mixture described. The results represent the fmol $\left[{ }^{14} \mathrm{C}\right]$ choline incorporated into PAF per embryo per min of incubation time.

Acetyltransferase activity also increased with the concentration of embryo homogenate present (Fig. 3) and the incubation time, with a plateau occurring after $120 \mathrm{~min}$ (Fig. 2). No activity was detected in the absence of lysoPAF, or when extracts were boiled for $15 \mathrm{~min}$ prior to assay (Table 1 ). The absence of $\mathrm{NaF}$ (a phosphatase inhibitor) reduced activity

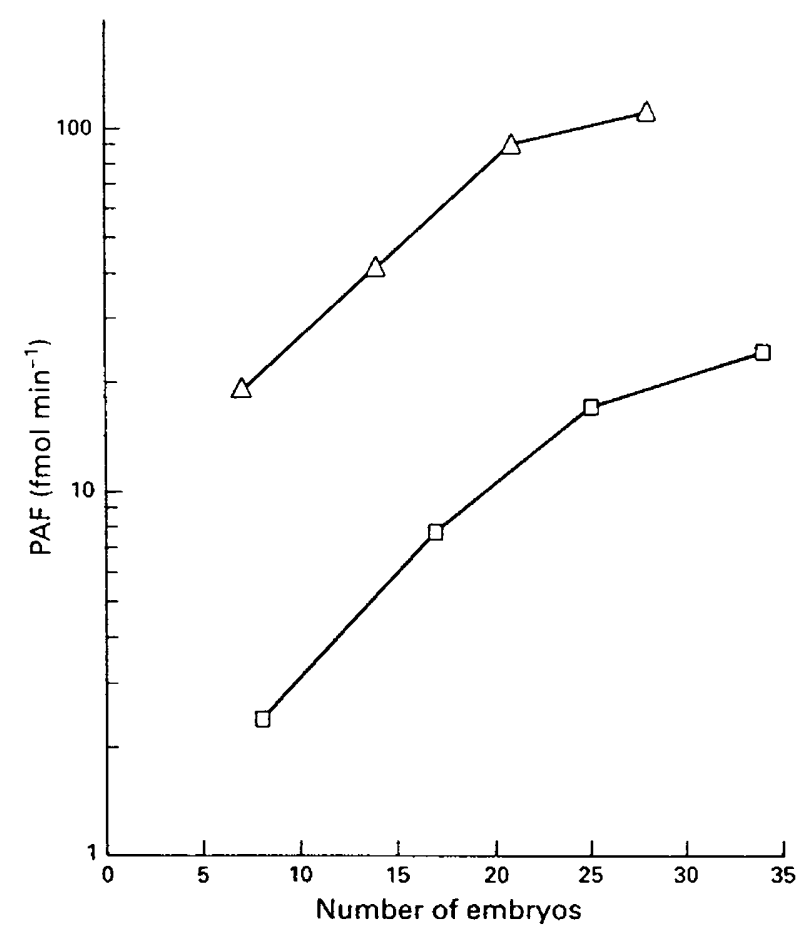

Fig. 3. The activity of $(\square)$ acetyltransferase and $(\Delta)$ cholinephosphotransferase in the presence of increasing concentrations of mouse embryo homogenates. The abscissa values represent the equivalent number of embryos in the homogenate added to the assay. Acetyltransferase assays were incubated for $180 \mathrm{~min}$ and cholinephosphotransferase assays for $30 \mathrm{~min}$. Each point represents the mean of two experiments. PAF; platelet-activating factor.

$(P<0.01)$ to $9.1 \%$ of the control activity (Table 1). Standard conditions for assessing the specific activity of acetyltransferase were defined as the activity in the extracts of 30 embryos or oocytes following a $180 \mathrm{~min}$ incubation period in the reaction mixture. The results represent $\mathrm{fmol}\left[{ }^{3} \mathrm{H}\right]$ acetate incorporated into PAF per embryo per min of incubation time.

The products of both reactions were confirmed to be PAF by structural analysis with enzyme digestion. The products of several reactions were pooled and, after hydrolysis by phospholipase $A_{2}, 87 \%$ of the total radioactivity produced by the cholinephosphotransferase reaction co-migrated with lysoPAF on HPLC. Treatment of the acetyltransferase reaction product with phospholipase $C$ resulted in $89 \%$ of the total radioactivity detected in the profile co-migrating with alkylacetylglycerol.

The specific activity of the two enzymes was compared in unfertilized oocytes and zygotes of the same age. The activity in embryos throughout the preimplantation period of pregnancy was also assessed. For acetyltransferase, the activity in unfertilized oocytes collected $24 \mathrm{~h}$ after hCG injection was significantly lower $(0.078 \pm 0.044 \mathrm{fmol}$ PAF per oocyte per $\min ^{-1}$, mean \pm SEM, $\left.n=4\right)$ than that found in zygotes of equivalent age $(0.358 \pm 0.097 \mathrm{fmol}$ PAF per zygote per min, $n=6)(P<0.03, t$ test $)$. By comparison, there was no significant difference $(P>0.05, t$ test) in the activity of cholinephosphotransferase between unfertilized oocytes $(3.298 \pm 1.080 \mathrm{fmol}$ $\mathrm{PAF}$ per oocyte per $\min , n=3)$ and zygotes $(2.307 \pm 0.400$, $n=3)$. 
Table 1. The effect of various treatments of mouse embryo homogenates or modifications to the assay buffer on the relative activity of cholinephosphotransferase and acetyltransferase

\begin{tabular}{llc}
\hline Enzyme & Treatment & Activity (\% of control (mean \pm SEM)) \\
\hline Cholinephosphotransferase & Control & 100 \\
& Boiling (15 min) & 0 \\
& - DDT & $108.3 \pm 13.4$ \\
& - alkylacetylglycerol & 0 \\
& - EGTA & $82.8 \pm 3.5$ \\
& $-\mathrm{Mg}^{2+}$ & $8.6 \pm 1.7$ \\
& - EGTA, $+\mathrm{Ca}^{2+}$ & $6.2 \pm 0.7$ \\
Acetyltransferase & Control & 100 \\
& Boiling (15 min) & 0 \\
& - lysoPAF & 0 \\
& $-\mathrm{NaF}$ & $9.1 \pm 6.7$
\end{tabular}

DTT: dithiothreitol.

Cholinephosphotransferase activity was variable within and between developmental stages of the preimplantation period. There was a trend for the activity to be highest at the two-cell stage ( $48 \mathrm{~h}$ after hCG injection) with a reduction of activity with increasing time of development; however, this trend was not significant $(P>0.05)$ (Fig. 4a). Acetyltransferase activity showed considerable variability for all stages of development (Fig. 4b). The activity found in two-cell stage embryo homogenates was significantly higher than in compacted embryos (72 h after hCG administration) $(P<0.01)$, while zygotes and blastocysts had intermediate values $(P>0.05)$.

\section{Discussion}

This paper reports the first successful detection of the PAF biosynthetic enzymes, cholinephosphotransferase and acetyltransferase in extracts of oocytes, zygotes and preimplantation embryos. The results confirm the observation of feeding experiments in vitro (Wells and O'Neill, 1992), which showed that embryos can biosynthesize PAF. Together, the results of these two studies suggest that the release of PAF by embryos is probably due to its synthesis rather than solely due to the release of preformed stores.

For both the cholinephosphotransferase and acetyltransferase reactions, the activities were heat labile and dependent upon the time that the reaction was allowed to proceed, and was linear with increasing concentrations of embryo homogenates. Such results indicate that the reactions were enzymatically catalysed. The radioactive product of the reactions can be considered to be PAF since it migrated with authentic PAF during HPLC, while enzymatic digestion of the reaction products by phospholipase $A_{2}$ and phospholipase $C$ resulted in the expected degradation products.

Embryonic cholinephosphotransferase activity was not affected by the presence of $5 \mathrm{mmol}$ DTT $\mathrm{l}^{-1}$. This property is similar to cholinephosphotransferase activities of the de novo pathway of PAF synthesis in various rat tissues (Renooij and Snyder, 1981; Woodard et al., 1987). The finding that the activity was not significantly higher in the absence of DTT
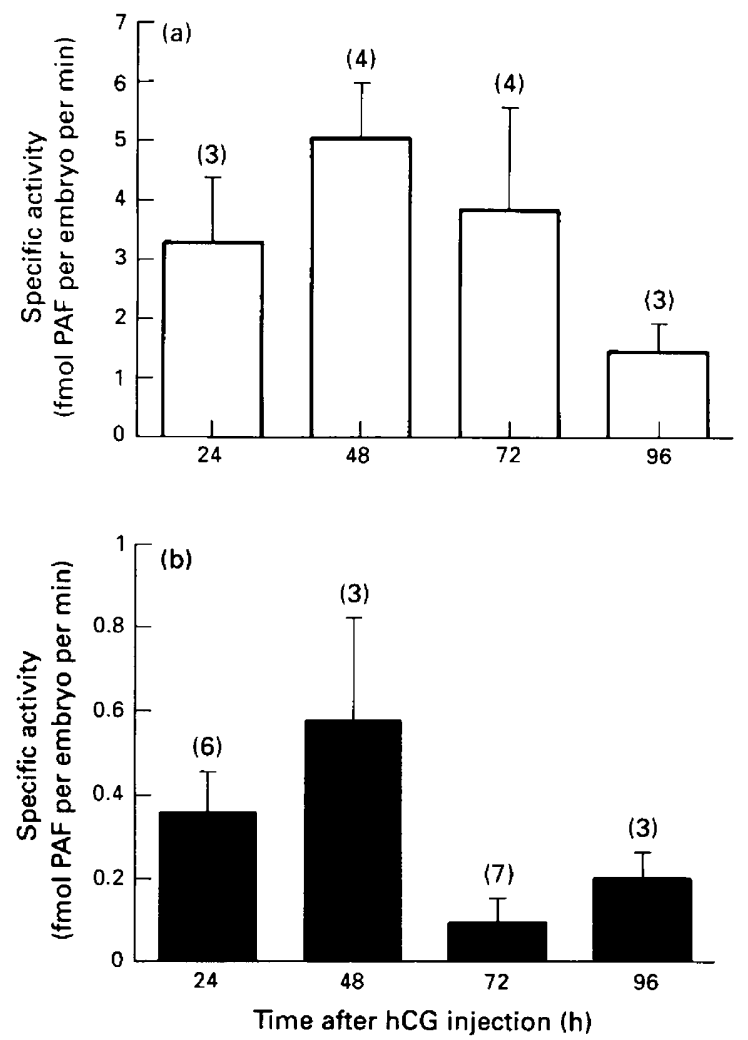

Fig. 4. The specific activity of (a) cholinephosphotransferase and (b) acetyltransferase at various times throughout the preimplantation phase of pregnancy in mice. Each bar represents the mean \pm SEM of the number of experiments shown in brackets above each bar. PAF: platelet-activating factor.

leads to the suggestion that DTT-insensitive cholinephosphotransferase was the only enzyme present in the embryo that could add phosphocholine to alkylacetylglycerol. This study does not exclude the possibility that the enzyme activity present may also be capable of catalysing the conversion of 1-O-alkyl-2-long chain acyl-sn-glycerol to 1-O-alkyl-2-long 
chain acyl-sn-glycero-3-phosphocholine, a precursor of PAF in the membrane remodelling pathway (see Wells and O'Neill, 1992).

The insensitivity of cholinephosphotransferase to DTT has been used as a means of distinguishing it from another cholinephosphotransferase activity that is implicated in the synthesis of phosphatidylcholine (Woodard et al., 1987). The sensitivity of the embryonic cholinephosphotransferase to $\mathrm{Ca}^{2+}$ and its requirement for $\mathrm{Mg}^{2+}$ illustrates further similarities with the DTT-insensitive cholinephosphotransferase of other tissues (Woodard et al., 1987).

The inhibition of acetyltransferase activity in the absence of $\mathrm{NaF}$ (a phosphatase inhibitor) from the reaction mixture suggests that the embryonic enzyme may be regulated by its phosphorylation state, and confirms its similarity in this regard to this type of acetyltransferase from other sources (Lenihan and Lee, 1984). This study does not exclude the possibility that the enzyme activity may also be capable of converting 1-O-alkyl-2-lyso-sn-glycero-3-phosphate to 1-O-alkyl-2-acetylsn-glycero-3-phosphate, a precursor of alkylacetylglycerol in the de novo biosynthetic pathway. In rat spleen tissue, these two activities have been differentiated by studies of $\mathrm{pH}$ optima, sensitivity to preincubation temperatures and substrate inhibition studies (Lee et al., 1986). Such detailed characterization was beyond the scope of this study.

Both enzymes required exogenous lipid substrate for activity, suggesting that under the conditions of the assay, there was no significant accumulation of endogenous precursors in the embryo homogenates. In the case of cholinephosphotransferase, this is in contrast to the situation in the inner medulla of the rat kidney (Woodard et al., 1987).

It has been reported that the release of PAF (Ammit and O'Neill, 1991) and the conversion of radiolabelled substrates into radiolabelled PAF released by embryos (Wells and O'Neill, 1992) is highly variable. In this study, the activity of both enzymes studied was also highly variable. Despite this variability, it was possible to detect a significant increase in the activity of acetyltransferase in fertilized embryos. Cholinephosphotransferase by contrast was not different in oocytes and zygotes, with a consistently higher specific activity than acetyltransferase.

The activation of acetyltransferase in the zygote suggests that its activity may be of regulatory significance for the synthesis of embryo-derived PAF, as it corresponds to the time that PAF release is first observed (O'Neill, 1985b). It has been adequately demonstrated in a variety of cell types that acetyltransferase may be activated after increase of the intracellular $\mathrm{Ca}^{2+}$ concentration by ionophores and that activation also requires phosphorylation of the enzyme, possibly by protein kinase $C$ (Lenihan and Lee, 1984). Pulsatile increases in intracellular $\mathrm{Ca}^{2+}$ concentration are known to occur in mouse zygotes (Swann, 1992), while the requirement for $\mathrm{NaF}$ to detect embryo acetyltransferase is consistent with a requirement for the enzyme to be phosphorylated. Further studies will indicate whether this is the mode of regulation of embryonic acetyltransferase.

Measurement of specific activity of enzymes in embryo homogenates does not necessarily reflect the activity of these enzymes in situ. It is not valid to extrapolate results from such studies to the biosynthetic activity of the embryo, and even less valid to make suppositions about the relationship between the enzymatic activity studied here and the amount of PAF released by embryos in vivo.

The authors thank J. Brassat and D. Gainsford for their technical assistance with the assays and chromatography. This work was supported by the National Health and Medical Research Council of Australia, grant number 890591 .

\section{References}

Adamson LM, Podsiadly B, Smart YC, Stanger JD and Roberts TK (1991) Studies on murine embryo-derived platelet-activating factor (EDPAF) Molecular Reproduction and Development 30 207-213

Alonso F, Gil MG, Sanchez-Crespo M and Mato JM (1982) Activation of 1-alkyl-2-lyso-glycero-3-phosphocholine. Acetyl-CoA transferase during phagocytosis in human polymorphonuclear leukocytes Journal of Biological Chemistry 257 3376-3378

Amiel ML, Duquenne C, Benveniste J and Testart J (1989) Platelet aggregating activity in human embryo culture media free of PAF-acether Human Reproduction 4 327-330

Ammit AJ and O'Neill C (1991) Comparison of a radioimmunoassay and bioassay for embryo-derived platelet-activating factor Human Reproduction 6 872-878

Battye KM, Ammit AJ, Evans G and O'Neill C (1991) Production of platelet activating factor in vitro by preimplantation sheep embryos Journal of Reproduction and Fertility 93 507-514

Bligh EG and Dyer WJ (1959) A rapid method of total lipid extraction and purification Canadian Journal of Biochemistry $258911-918$

Collier M, O'Neill C, Ammit AJ and Saunders DM (1988) Biochemical and pharmacological characterisation of human embryo-derived platelet activating factor Human Reproduction 3 993-998

Kodama H, Muto H and Maki M (1989) Isolation and identification of embryoderived platelet-activating factor in mice Acta Obstetrics and Gynaecology Japan 41 899-906

Lee T-C (1985) Biosynthesis of platelet activating factor. Substrate specificity of 1-alkyl-2-lyso-sn-glycero-3-phosphocholine:acetyl-CoA acetyltransferase in rat spleen microsomes Joumal of Biological Chemistry $26010952-10955$

Lee T-C, Malone B and Snyder F (1986) A new de novo pathway for the formation of 1-alkyl-2-acetyl-sn-glycerols, precursors of platelet-activating factor. Biochemical characterization of 1-alkyl-2-lyso-sn-glycero-3-P:acetylCoA acetyltransferase in rat spleens Journal of Biological Chemistry 261 5373-5377

Lenihan DJ and Lee T-C (1984) Regulation of platelet activating factor synthesis: modulation of 1-alkyl-2-lyso-sn-glycero-3-phosphocholine:acetyl$\mathrm{CoA}$ acetyltransferase by phosphorylation and dephosphorylation in rat spleen microsomes Biochemical and Biophysical Research Communications $\mathbf{1 2 0}$ $834-839$

O'Neill C (1985a) Partial characterization of the embryo-derived plateletactivating factor in mice Joumal of Reproduction and Fertility 75 375-380

O'Neill C (1985b) Thrombocytopenia is an initial maternal response to fertilization in mice Journal of Reproduction and Fertility 73 559-566

O'Neill C (1993) The actions of platelet-activating factor (PAF) in the establishment of mammalian pregnancy. In Implantation in Mammals Vol. 19 pp 59-82 Eds L Gianaroli, A Campana and AO Trounson. Serono Symposium Publications, Raven Press, New York

O'Neill C, Gidley-Baird AA, Pike IL and Saunders DM (1987) Use of a bioassay for embryo-derived platelet activating factor as a means of assessing quality and pregnancy potential of human embryos Fertility and Sterility $\mathbf{4 7}$ 969-975

Punjabi U, Vereecken A, Delbeke L, Angle M, Gielis M, Gerris J, Johnston J and Buytaert Ph (1990) Embryo-derived platelet activating factor, a marker of embryo quality and viability following ovarian stimulation for in vitro fertilisation Journal of in vitro Fertilization and Embryo Transfer 7 321-326

Quinn P, Warnes GM, Kerin JF and Kirby C (1985) Culture factors affecting the success rate of in vitro fertilization and embryo transfer Annals of the New York Academy of Science 442 195-203

Renooij W and Snyder F (1981) Biosynthesis of 1-alkyl-2-acetyl-sn-glycero-3phosphocholine (platelet activating factor and a hypertensive lipid) by 
cholinephosphotransferase in various rat tissues Biochimica et Biophysica Acta $663545-556$

Smal MA, Dziadek M, Cooney SJ, Attard M and Baldo BA (1990) Examination for platelet-activating factor production by preimplantation mouse embryos using a specific radioimmunoassay Journal of Reproduction and Fertility 90 419-425

Snyder F (1990) Platelet-activating factor and related acetylated lipids as potent biologically active cellular mediators American Joumal of Physiology 259 C697-C708

Swann K (1992) Different triggers for calcium oscillations in mouse eggs involve a ryanodyne-sensitive calcium store Biochemical Journal 287 79-84
Wells XE and O'Neill C (1992) Biosynthesis of platelet-activating factor by two-cell mouse embryos Joumal of Reproduction and Fertility 96 61-71

Woodard DS, Lee T-C and Snyder F (1987) The final step in the de novo biosynthesis of platelet-activating factor. Properties of a unique CDPcholine:1-alkyl-2-acetyl-sn-glycerol cholinephosphotransferase in microsomes from the renal inner medulla of rats Joumal of Biological Chemistry 262 2520-2527

Wykle RL, O'Flaherty JT and Thomas MJ (1988) Platelet-activating factor Methods in Enzymology 163 44-54 